\title{
Universidade e commodity: um convite à leitura e à reflexão sobre a educação superior brasileira'
}

University and commodity: a reading and thinking on Brazilian higher education

Universidad y commodity: una invitación a la lectura y la reflexión sobre la educación superior brasileña

Renata Porcher Scherer Universidade do Vale do Rio dos Sinos

BIANCHETTI, Lucídio; SGUISSARDI, Valdemar. Da universidade à commoditycidade ou de como e quando, se a educação/formação é sacrificada no altar do mercado, o futuro da universidade se situaria em algum lugar do passado. Campinas: Mercado das Letras, 2017.

A obra "Da universidade à commoditycidade ou de como e quando, se a educação/formação é sacrificada no altar do mercado, o futuro da uni334 versidade se situaria em algum lugar do passado", escrita por Lucídio Bianchetti e por Valdemar Sguissardi, dois importantes pesquisadores do campo educacional, discorre sobre uma questão nevrálgica da educação contemporânea, oferecendo um diagnóstico importante sobre a educação superior no contexto brasileiro. O livro apresenta prefácio escrito por Almerindo Janela Afonso e está dividido em três capítulos.

No primeiro capítulo "Universidade, tutelas e políticas educacionais: da instituição medieval à moderna. Alguns antecedentes da situação atual", os autores têm como objetivo principal situar o tema do livro "[...] no espaço-tempo e relacioná-lo a seus objetivos e justificativas na constituição histórica [...]" (BIANCHETTI; SGUISSARDI, 2017, p. 17). Muito mais que um diagnóstico ou uma revisão histórica das políiticas públicas de educação superior, o capítulo oferece uma análise crítica da constituição histórica das universidades desde a ldade Média no contexto europeu.

Os autores sustentam que a universidade, desde o seu surgimento até o século XIX, passou por poucas transformações no seu modo de organização e de funcionamento, e, principalmente, na sua condição de "universidade tutelada". Assim, a sua origem é devida à necessidade de a Igreja Cristã formar 
seus quadros e que, com o advento reformista e contrarreformista, "[...] a universidade passará a ser mais um dos instrumentos de continuidade ou busca de hegemonia por parte da igreja [...]" (BIANCHETTI; SGUISSARDI, 2017, p. 18), indiferentemente de se assumir católica ou protestante.

No segundo capítulo, intitulado "Brasil: de instituições de ensino superior - passando por experiências fundantes - à regulação", os autores iniciam retomando a historicidade das universidades no contexto brasileiro. Até o final do Império, no Brasil se consolidou o modelo de faculdades isoladas. Outro destaque relativo às instituições brasileiras é a ausência de um caráter nacional sob forte influência colonialista e colonial.

Com base em uma revisão da literatura sobre a história da universidade brasileira, os autores destacam duas importantes reflexões: a primeira refere-se ao fato de que a universidade tem sido historicamente tutelada pelo Estado e por grupos que apresentam interesse por essa instituição. $\bigcirc$ segundo aspecto diz respeito ao papel periférico atribuído à educação "[...] e a preocupação com a formação humana em geral e, de professores em particular, nessas instituições de educação superior denominadas universidades" (BIANCHETTI; SGUISSARDI, 2017, p. 41).

Além de uma relevante retomada histórica da constituição das universidades brasileiras e de um importante estado da arte sobre o tema, o capítulo descreve o que os autores nomeiam como "três experiências fundantes (e fugazes!) de universidade" (BIANCHETTI; SGUISSARDI, 2017).

Os modelos no capítulo referem-se à Universidade de São Paulo, à Universidade do Distrito Federal e à Universidade de Brasília. Destaca-se em comum, nos três modelos, o foco na formação de professores em todos os níveis e fortes críticas ao autodidatismo "[...] que vinha caracterizando o trabalho docente - universitário e também em outros níveis - e a dependência de material vindo do exterior" (BIANCHETTI; SGUISSARDI, 2017, p. 60).

capítulo três, intitulado "Àcommoditycidade", com uma análise crítica e perspicaz do cenário atual da educação superior/universidade brasileira, faz pensar na necessidade de "[...] uma nova denominação para qualificar/ nominar aquilo que anteriormente, de forma tácita e quase uníssona, se concordava ao falar-se de uma instituição chamada universidade" (BIANCHETTI; SGUISSARDI, 2017 , p. 76). Para tanto, os autores sugerem a expressão "commoditycidade", buscando resumir as novas dimensões que 
estariam assumindo as IES em nosso país. $\bigcirc$ conceito é construído a partir da expressão commodity, bastante utilizada no campo econômico, em que a mercadoria a ser vendida, tem o seu valor calculado pela sua cotação no mercado, e não no custo de sua produção. Fatores políticos, sociais e culturais exercem forte influência na definição do preço dessas mercadorias.

A tese sustentada no livro da emergência do que eles denominaram de commoditycidade é mantida por dois fatores. $\bigcirc$ primeiro fator refere-se à abertura de capital das empresas educacionais. $O$ segundo consiste na "[...] formação de monopólios e oligopólios a partir da aquisição, função ou incorporação entre algumas das maiores empresas do setor educacional" (BIANCHETT; SGUISSARDI, 2017, p. 89). A ampliação da oferta de serviços em forma de cursos fastfood, para os autores, está relacionada à compreensão da educação como uma mercadoria na qual "[... a baixa qualidade formativa não somente é prioridade, como passa a ser uma necessidade" (BIANCHETTI; SGUISSARDI, 2017, p. 105).

$\mathrm{Na}$ conclusão da obra, os autores alertam, mais uma vez, para o perigo da mercadorização/mercantilização da universidade e o que nomeiam como "efeito bonsai" da educação/formação, quando esta é colocada no altar do mercado. Uma perspectiva utilitarista e pragmática acaba por se constituir na finalidade dessas instituições onde a relação aluno e universidade, acaba se constituindo numa relação cliente/fornecedor. Assim, o aluno "[...] comparece à universidade negociando o seu tempo e às vezes o seu próprio dinheiro ou aquele repassado pelo governo ao empresário para formar-se um profissional" (BIANCHETTI; SGUISSARDI, 2017, p. 109).

Interrogando "[...] o que resta de educação na educação em geral e de superior na educação superior [...]" (BIANCHETTI; SGUISSARDI, 2017,p. 1 10), os autores encerram esse provocativo trabalho que, certamente, constitui-se em leitura imprescindível para todos os que pesquisam sobre a educação superior e também para pesquisadores e professores de qualquer nível, pois nos alerta e interroga sobre os rumos da educação em tempos neoliberais e, ao descrever experiências fundantes, afirma que o futuro da educação pode estar em algum lugar do passado. 


\section{Nota}

1 presente trabalho foi realizado com apoio da Coordenação de Aperfeiçoamento de Pessoal de Nível Superior - Brasil (CAPES) - Código de financiamento 001.

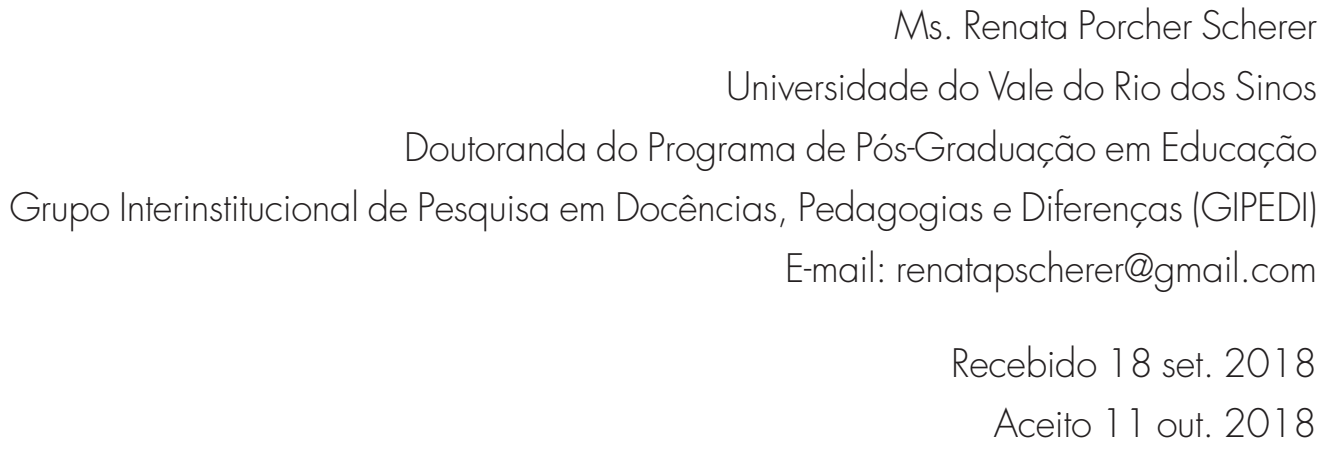

